\title{
Falx Cerebri
}

National Cancer Institute

\section{Source}

National Cancer Institute. Falx Cerebri. NCI Thesaurus. Code C12890.

A double-fold of dura mater that lies within the medial longitudinal fissure, and which separates the two cerebral hemispheres. It is attached rostrally to the crista galli and caudally to the surface of the tentorium cerebelli. 